\title{
Re-contextualizando la influencia extranjera en la historia de la educación en Japón: la (re) recepción de John Dewey
}

\author{
Re-Contextualizing Foreign Influence in Japan's \\ Educational History: the (Re)Reception of \\ John Dewey
}

\author{
Recontextualiser l'influence étrangère sur \\ I'histoire de l'éducation au Japon: le nouvel \\ accueil de John Dewey
}

\author{
Jeremy Rappleye \\ University of Oxford, Reine Unido
}

\section{RESUMEN}

Este trabajo explora la recepción y re-recepción de John Dewey en el contexto japonés. Aunque la visita de dos meses de Dewey a Japón durante la primavera de 1919 coincidió con el esperanzador movimiento demócrata Taishō, al parecer sus ideas tuvieron escaso impacto en un panorama político, intelectual y educacional dominado por una interacción compleja entre ideas neo confucianas, nativistas y germanas. Sin embargo, la historia no acaba allí; luego de la Segunda Guerra Mundial, hubo un notable 'auge' de Dewey por todo Japón durante más de una década, lo que sobrepasó por mucho su recepción original en 1919. Aquí nos encontramos con un Dewey que es crucial para la modernización de los debates sobre reformas y punto central para la reinterpretación de la historia educacional de preguerra en Japón. Dado este curioso resurgimiento y paradoja de interés creciente en Dewey, pocos contextos nacionales parecieran agrupar más evidencia que el de Japón para apoyar la idea de que los cambios políticos e ideológicos matizan las definiciones de lo que se considera como 'conocimiento' educacional.

Descriptores: John Dewey; procesos de recepción; transferencia educacional; historia educacional japonesa.

\section{ABSTRACT}

This work explores John Dewey's reception and re-reception in the Japanese context. Although Dewey's two-month visit to Japan in the spring of 1919 coincided with the hopeful Taishō 
democracy movement, his ideas appear to have made little impact in a political, intellectual, and educational landscape dominated a complex interplay of traditional neo-Confucian, nativist, and German ideas. Yet the story does not end there: following World War II, there was a remarkable Dewey 'boom' across Japan lasting more than a decade that far surpassed Dewey's original reception in 1919. Here we find Dewey central to revamped reform debates and a focal point for the reinterpretation of Japan's prewar educational history. Given this curious resurgence-cum-paradox of increasing interest in Dewey, few national contexts would seem to hold more evidence than Japan in support of the idea that political and ideological shifts qualify definitions of what counts as educational 'knowledge.'

Key words: John Dewey; reception processes; educational transfer; Japanese educational history.

\section{RÉSUMÉ}

Ce travail explore l'accueil et le nouvel accueil fait à John Dewey dans le contexte japonais. Quoique la visite de John Dewey au Japon durant deux mois au printemps 1919 coïncidait avec le mouvement démocratique prometteur de Taishō, ses idées semblent n’avoir eu que peu d'impact dans un contexte politique, intellectuel et éducatif dominé par une interaction complexe d'idées néo-Confucéennes, nativistes et allemandes. Cependant, l'histoire ne finit pas là : après la deuxième guerre mondiale, il y eut un "boom " Deweyen remarquable à travers le Japon qui dura plus d'une décennie, surpassant de loin l'accueil originel de Dewey en 1919. Ici, nous trouvons Dewey au centre des débats renouvelés pour la réforme et pour la ré-interprétation de l'histoire de l'éducation d'avant-guerre au Japon. Étant donnée cette étrange réapparition paradoxale d'un intérêt grandissant pour Dewey, peu de contextes nationaux sembleraient démontrer plus de preuves que le japon en faveur de l'idée que les revirements politiques et idéologiques doivent entrer dans la définition de ce qui est considéré comme " connaissance " éducationnelle.

Mots clés : John Dewey; le processus d'accueil; le transfert éducationnel; I'histoire de l'éducation japonaise.

\section{Introducción}

Q UIZÁ EN NINGUNA OTRA PARTE DEL MUNDO el entusiasmo generado por John Dewey fue mayor que en Japón. En el breve lapso de poco más de diez años, alrededor de ciento cincuenta libros y artículos desplazaron a los tomos tradicionales sobre educación, inundando las estanterías y los periódicos académicos de todo el país; traducciones de las obras de Dewey se sucedieron con gran rapidez y estudiantes de la Universidad de Hokkaido, en el norte, celebraron una solemne velada 'John Dewey' mientras otros alumnos de la Ehime sureña y rural inauguraron un bullicioso y colorido 'Festival Dewey'. El servicio nacional de transmisión japonés, NHK, transmitió un programa titulado 'La filosofía de Dewey y la educación japonesa' para una audiencia de millones en todo Japón. Incluso el ministerio de educación - considerado un bastión del conservadurismo educacional — reconoció las ideas innovadoras y progresistas de Dewey en su 'Dictionary of Education.'Algunos estudiosos formaron la Sociedad John Dewey de Japón, como un foro para la lectura y el debate sobre la filosofía del autor. Quizá el hecho más destacable sea que, en apenas diez años, jóvenes estudiantes enviaran más de 250 exposiciones a universidades japonesas, apasionados por las ideas de un hombre que, no olvidemos, visitó el país durantes breves tres meses, en la fría primavera de 1919.

Quienes tienen la imagen de un sistema educacional japonés uniforme, disciplinado 
y adusto - o cualquier concepto menos experiencial, democrático y progresista - encontrarán sorprendentes estos hechos. Sin embargo, aún más sorprendente es el hecho de que esta apasionada recepción de Dewey haya ocurrido alrededor de tres décadas después de la visita del autor para dictar cátedras en el país. De hecho, los eventos antes descritos tomaron curso entre mediados de la década de 1940 y mediados de los años 50. Las traducciones de los clásicos de Dewey, 'Experience and Education' y 'Democracy and Education', se publicaron en 1950 y 1952, respectivamente. Las celebraciones en las universidades también datan de mediados de la década de 1950; la transmisión de NHK salió al aire en 1955 y el 'Dictionary of Education' fue publicado poco antes, en 1949. La Sociedad John Dewey de Japón se inició en 1957, casi cuatro décadas después de la visita de Dewey y cinco años después de su propia muerte. De manera extraordinaria, la 'Dewey-manía' de posguerra sobrepasó por mucho cualquier evento anterior o posterior, incluida su visita en persona. Entonces, ¿cómo se explica este 'auge' repentino y sin precedentes por Dewey?, ¿como se justifica este resurgimiento-cum-paradoja de la recepción de Dewey en Japón? ${ }^{1}$

Contextualizada en estas preguntas amplias, la recepción de Dewey en Japón presenta una perspectiva única tanto de su influencia a nivel mundial como de problemas más amplios sobre la dinámica de la transferencia educacional. Se podría decir que pocos registros nacionales sobre la recepción e influencia de Dewey parecieran revelar en tal medida como los cambios en las configuraciones políticas, las ideologías dominantes y el contexto social producen fluctuaciones profundas en lo que se puede considerar como 'conocimiento' educacional. No hay mayor evidencia sobre esto que treinta años de indiferencia hacia las ideas de Dewey que repentinamente florecen para transformarse en la constelación de cambios políticos y sociales ocurridos en Japón durante la década que siguió a la Segunda Guerra Mundial. Al situar a Dewey entre las tradiciones intelectuales preexistentes y las realidades políticas en evolución, el estudio revela como sus ideas fueron adoptadas, interpretadas y reinterpretadas de manera selectiva, de acuerdo con el cambiante entorno contextual cultural, social e ideológico de Japón en un proceso complejo cuyo inicio se remonta a fines del siglo XIX y continúa incluso hasta hoy.

\section{Resaltando el contexto y la continuidad: tres tradiciones intelectuales japonesas dominantes}

$\mathrm{Al}$ hacer un recuento de la recepción de Dewey en Japón, el estudioso se enfrenta a la decisión inmediata, aunque crucial, sobre cuál será el foco de su investigación: Dewey o Japón. En otras palabras, debe decidir si el informe girará en torno a Dewey, detallando como Japón apareció en su mundo o, por el contrario, partirá del contexto japonés para luego llegar a su interacción con Dewey. Si tomamos imaginería del ambiente teatral las preguntas serían: ¿El informe presentará al teórico en el papel principal, cambiando su escenario a medida que desarrolla la trama? o ¿Dewey aparecería y reaparecería a medida que avanza el drama del Japón moderno? La decisión es mucho más que estética, aunque los resultados no son menos dramáticos.

El primer enfoque, centrado en Dewey, ha sido claramente más atractivo para la 
literatura en inglés, ${ }^{2}$ en parte debido a que se basa en su gran mayoría en los propios relatos de Dewey, de los cuales Letters from China and Japan (1920) resalta de manera más prominente. El segundo enfoque no ha sido tan utilizado, aunque hay excepciones notables. ${ }^{3}$ No obstante, hay mucho en juego en esta elección de perspectiva, en especial si se considera la recepción de Dewey en Japón como un medio para sacar a la luz la dinámica de los flujos transnacionales de conocimiento. Como plantea Steiner-Khamsi: ${ }^{4}$

Si los investigadores se enfocan en el contenido de la transferencia, no hay duda de que encontrarán un denominador común [...] sin embargo, si escogemos dar prioridad al contexto local [...] y preguntar porque una idea o discurso se ha transferido, logramos una comprensión completamente distinta de la transferencia.

De hecho, es necesario un recuento de la recepción de Dewey en Japón que, respondiendo llamados como el de Steiner-Khamsi a poner el contexto local en primer plano, haga una contribución fresca a la literatura ya existente sobre este hecho. ${ }^{5}$ Sin embargo, no es tarea fácil detallar el contexto de ningún lugar, mucho menos de uno tan ampliamente representado como enigmático y con frecuencia cargado de exoticismo como Japón. Es necesaria una apreciación de las continuidades que no trivialice el cambio, que muestre la transformación sin borrar la forma original.

Así, la narrativa histórica que sigue ubica el cambiante contexto en el que las ideas de Dewey fueron interpretadas, contextualizadas y apropiadas en cinco períodos diferentes: post-restauración Meiji, democracia Taishō, Segunda Guerra Mundial, ocupación de posguerra y década de 1960 hasta el presente. Al mismo tiempo, la historia de las tradiciones intelectuales en desarrollo provee un elemento de continuidad que une estos períodos en un todo cohesivo y entrelaza la recepción de Dewey con el brocado intelectual del Japón moderno. Aquí, sin embargo, la complejidad de desentrañar el impacto de las fuerzas exógenas en el contexto local no puede nacer y morir en simples dualidades entre lo interno y lo externo, entre lo extranjero y lo aborigen. En el caso de Japón, como quizá sucede en otros lugares, el hilo de continuidad (las tradiciones intelectuales aborígenes) en realidad revela ser una intrincada trenza luego de una observación más detenida: tres diferentes tradiciones de conocimiento que anteceden, ayudan a formar y luego persisten en el Japón moderno. Se debe considerar cada una de estas hebras, cada una debe ser confrontada con las ideas de Dewey, para comprender a cabalidad su recepción e impacto (o ausencia de este) en contexto.

La primera de estas ideas neo confucianas se originó en China alrededor de mil años antes, sólo para ser reinterpretada y trabajada a través de los siglos, ${ }^{6}$ que engendra al Japón moderno, emerge como una poderosa elite ideológica con un impacto dominante en la educación, que legitimó un sistema jerárquico que giraba en torno al cultivo de la moralidad regida por un único líder:

De acuerdo con el neo confucianismo de Tokugawa, el propósito de estudiar a los clásicos chinos era descubrir el principio moral eterno e inmutable que 
gobierna tanto al mundo natural como a la sociedad humana. A partir de esto, mantener la paz y la armonía en la sociedad era por mucho cuestión de que el líder aplicara este conocimiento para rectificar su propia persona y su conducta para con los demás y, de esta manera, ser un ejemplo de virtud para que los demás lo siguieran, cada uno de acuerdo con su propia posición en la jerarquía social. $^{7}$

Con este fuerte énfasis en la moralidad, en las virtudes confucianas clásicas como la lealtad, la piedad filial, la justicia y la armonía mediante la jerarquía de las relaciones sociales, el neo confucianismo trajo un proyecto educacional muy específico: educación moral explícita, cultivo de las relaciones de grupo, respeto por las imágenes de autoridad (profesores y padres) y énfasis en la armonía con la naturaleza. ${ }^{8}$

Una segunda tradición intelectual era el nativismo (kokugaku). ${ }^{9}$ Lincicome ${ }^{10}$ describe una tradición opuesta a la ortodoxia neo confuciana que "rechazaba la imitación servil de las instituciones chinas y la fidelidad a los textos chinos en favor del redescubrimiento de la esencia superior del espíritu de la cultura nativa, manifestado en los textos japoneses antiguos." El nativismo se identificaba naturalmente con la religión aborigen Shintō en oposición al budismo, frecuentemente desacreditado junto al neo confucianismo como otra debilitante importación china. Cuando la Restauración Meiji (1868) terminó con el monopolio neo confuciano sobre la producción del conocimiento, los estudiosos nativistas aparecieron de inmediato para establecer la importancia de los estudios japoneses. Incluso ya en 1869, las tensiones resultantes eran visibles en la educación:

... hirvió el debate entre las facultades de nativismo y de estudios chinos sobre la dirección adecuada de la educación en las universidades y, por ende, en todo el país [...] finalmente, ninguna parte clamó victoria y durante todo el año siguiente cada campus donde se enseñaba ambas doctrinas era cerrado, lo que permitió sólo a las facultades y a los estudiantes de estudios occidentales y aprendizaje médico ganar protagonismo. ${ }^{11}$

A pesar de su tendencia a ver la Restauración Meiji como el triunfo de su defensa del Trono Imperial, el nativismo tendría un papel relativamente menor al inicio de la modernidad japonesa. Sin embargo, su influencia crecería de manera sustancial en las décadas siguientes $\mathrm{y}$, como algunos han argumentado, ${ }^{12}$ resultó triunfar a fines de la década de 1920 e inicios de la de 1930, entregando gran parte de la base ideológica para el ultra-nacionalismo y militarismo emergente del Japón Imperial y su programa educacional marcadamente nacionalista.

La tercera tradición intelectual más importante eran los estudios occidentales (yögaku) que habían evolucionado lentamente desde su contacto inicial con los misioneros occidentales en el siglo XVI. En un principio menospreciados como "estudios bárbaros" (nanbangaku), desde su inicio estuvieron fuertemente engranados con la cristiandad y por eso se transformaron en una fuente de sospechas, ya que "representaban un nuevo foco de autoridad y un nuevo cuerpo de conocimiento que competía 
con las doctrinas aceptadas por el reconocimiento popular." ${ }^{13}$ De todas maneras, esta tradición era considerada mucho más práctica en relación con la doctrina neo confuciana y la nativista, ya que trataba temas como la astronomía y la navegación, al igual que la medicina y principios científicos, lo que la hizo aceptable a los ojos de muchos. Estos "estudios bárbaros" se transformaron en estudios holandeses (rangaku) cuando el contacto con extranjeros se limitaba a los mercaderes holandeses durante el aislamiento japonés autoimpuesto (sakoku), solo para volver a transformarse, esta vez en estudios occidentales al inicio de la modernización Meiji. Como se describe a continuación, en las turbulentas décadas que siguieron a la Restauración Meiji el aprendizaje occidental y, por extensión, las formas educacionales de occidente iban en ascenso e incluso dominaban. Incluso llegó a parecer que los estudios occidentales relegarían por completo a las otras dos tradiciones a la historia previa al modernismo en Japón. Afortunadamente, la historia es mucho más compleja, tanto como ubicar a Dewey en este rico, intrincado y fascinante entorno intelectual.

Es importante notar que a pesar del aparente orden de la descripción comprimida y simplificada que se presenta aquí, las fusiones de estas tres tradiciones (neo confuciana, nativista y occidental) a menudo emergieron de contextos políticos y sociales particulares. ${ }^{14}$ La Escuela Mito (mitogaku), por ejemplo, atrajo muchos adherentes a sus academias privadas a fines del período Tokugawa y principios del Meiji con su enfoque que unía "la creencia neo confucianista en un orden social natural con la visión nativista de elevar de la cultura japonesa por sobre la china y llamaba a propagar esta esencia cultural y espiritual nativa como una religión nacional, con un poder equivalente al de la cristiandad occidental." ${ }^{15}$ De hecho, es la interacción, el conflicto y la fusión de estas tres tradiciones lo que entrega a la historia moderna de Japón gran parte de su textura e inescrutabilidad, pero también de dinamismo. Como uno de los teóricos sociales más destacados, S.N. Eisenstadt explica:

es probablemente el continuo encuentro de Japón con China, con el confucianismo y con el budismo y más tarde con occidente, además de la permanente necesidad de diferenciarse de China y de occidente sin negar los valores externos o admitir su superioridad, lo que ha llevado al desarrollar esta forma intensa, compleja y sofisticada de discurso ideológico que distingue a Japón de otras civilizaciones no-axiales. ${ }^{16}$

Al igual que el particular sistema de escritura japonés, que preserva el origen de las palabras chinas (kanji), conceptos nativos japoneses (hiragana) e importaciones de occidente (katakana), incluso logrando hacer fluída y funcional esta alianza que de otra forma sería complicada, el contexto intelectual y educacional japonés se puede conceptualizar de manera bastante similar. Aunque quizá, a diferencia de la escritura japonesa, las tensiones entre estas tres tradiciones intelectuales se deben considerar fundamentalmente como una sola de constante competencia y fluidez, en que cada bando se realinea y reposiciona de acuerdo con las rápidamente cambiantes condiciones sociales y en relación con las otras tradiciones. En medio de esta lucha, el conocimiento y las formas en la educación se volvieron altamente disputadas y cada bando 
buscaba maneras de inclinar la balanza intelectual, reinterpretando el pasado, refutando el presente y (el mayor de nuestros propósitos) 'exteriorizándose' ${ }^{17}$ a eventos e ideas fuera de Japón. Comprender esta interacción de tradiciones intelectuales en el contexto Japonés es el punto de inicio para desarrollar una noción más profunda de la recepción de Dewey en Japón.

\section{Restauración Meiji a $1^{a}$ Guerra Mundial: Saber occidental (alemán) con compromiso, Dewey se escabulle}

John Dewey tenía apenas nueve años cuando la Restauración Meiji terminó con cerca de tres siglos de aislamiento auto impuesto (sakoku) en Japón. Con decretos como "se debe acabar con las costumbres malvadas del pasado" y "se debe buscar el conocimiento por todo el mundo," impuso el aprendizaje occidental por sobre las tradiciones neo confucianas y nativistas. ${ }^{18}$ Sin embargo, los decretos imperiales (como la mayoría de las políticas educacionales del presente) no pueden alterar con facilidad las tradiciones indígenas empotradas. En los caóticos años que siguieron a la Restauración, las tradiciones nativistas se deleitaron con el retiro del apoyo estatal a la hegemonía confuciana del conocimiento. Buruma ${ }^{19}$ indica una serie de actos altamente simbólicos luego de la Restauración que revelaron las permanentes tensiones, como cuando "fanáticos Shintō empezaron a destruir templos budistas, en un esfuerzo por limpiar a Japón de sus tradiciones culturales chinas." El autor explica que "las ideas occidentales motivaron a los nativistas japoneses; ayudaron a emancipar a Japón de la órbita cultural china." ${ }^{20}$ Así, claramente, a pesar del aparente triunfo de algunas formas occidentales, la Restauración Meiji en realidad sólo había hecho renacer una lucha de poder entre las tradiciones intelectuales preexistentes, que se había suspendido (o había pasado a ser subrepticia) a causa del previo apoyo estatal al confucianismo. Durante las cinco décadas que precedieron a la visita de Dewey a Japón, estas tradiciones rivales continuarían su lucha por el poder en casi todas las esferas de la vida social y política, pero en ninguna de manera tan marcada como en la educación. ${ }^{21}$ Ningún análisis de la recepción de Dewey puede permitirse pasar por alto las luchas monumentales que precedieron a su llegada.

En la primera década que siguió a la Restauración, el aprendizaje occidental realmente parecía ascendente. La famosa Misión Iwakura (1871-1873) envió a casi todo el gobierno Meiji en un viaje de 21 meses a descubrir los secretos de la 'civilización' y el prestigio occidental. Se anunció a la educación como una fuente principal de poder occidental y la Misión trajo de vuelta una mezcla ecléctica de características educacionales de varias naciones de occidente; ${ }^{22}$ más aún, el gobierno gastó una fracción considerable del presupuesto nacional de educación en enviar estudiantes a otros países e invitó a cientos de extranjeros a Japón. Estos tutores del saber occidental fueron conocidos como oyatoi gaijin y se asemejan a los expertos en asistencia técnica del aparato de desarrollo actual. ${ }^{23}$ Algunos alcanzaron connotadas posiciones en el gobierno, como un David Murray que fue superintendente del departamento de educación y ayudó a fundar la Universidad de Tokio. De hecho, la historia de la recepción de Dewey en Japón pudo haber sido muy diferente si él hubiese llegado en aquellos 
años en que el drástico cambio político volvió a Japón extremadamente receptivo a las ideas educacionales, pero desgraciadamente Dewey ni siquiera se había graduado de la educación secundaria (ni hablar de la universidad) al otro lado del mundo. Por el contrario, la reacción de fuerzas internas contra una década de saber occidental desbocado ya se había iniciado en Japón.

Desde alrededor de 1880, la tradición nativista empezó a notar el considerable poder y la amenaza que representaba el saber occidental y, pausadamente, montó una contraofensiva cuya premisa era una coalición con la, alguna vez odiada, tradición neo confuciana. ${ }^{24}$ De hecho, esta última ya trabajaba vigorosamente desafiando el flujo de conocimiento occidental. Motoda Nagazane, un orador confuciano del emperador, se quejó de que las reformas educacionales habían "puesto demasiado énfasis en la adquisición de saberes y métodos occidentales" y una vez más llamó al "estudio de la moralidad basada en Confucio." ${ }^{25}$ Crecientes esfuerzos en líneas similares llevaron a una revisión sustancial y conservadora de la Ley de Educación (1881) y a gestiones del Ministerio de Educación para limitar el uso de las escuelas para reuniones de tipo político (1883).

El conocimiento tradicional (un eslogan emergente, posibilitado por la cercana alianza entre los nativistas y los neo confucianos) empezó a ser visto como digno de 'recuperar' como un suplemento espiritual a la sobre exposición de la modernización occidental. ${ }^{26}$ Esto hizo que la oligarquía Meiji, que parecía tan progresista (léase: occidental) en la década anterior, empezara a verse cada vez más conservadora. Este hecho tuvo profundas implicancias, que un Japón en aprendizaje occidental decidió asimilar. Swale, ${ }^{27}$ por ejemplo, destaca un cambio desde el individualismo de John Stuart Mill al énfasis más colectivo del darwinismo social de Spencer; en tanto Hoston ${ }^{28}$ muestra que entre los japoneses de tendencia liberal hubo un cambio marcado hacia líneas liberales, que enfatizaban una perspectiva social mayor en el individuo, rechazando la legitimidad de lo privado en relación con lo público, mas acorde con las tradiciones japonesas, de orden más comunitario.

Este clima colectivo, cada vez más conservador, tuvo profunda influencia para el 'referente social' de elección: desde el eclecticismo de la Misión Iwakura que se fortaleció en muchos sistemas, hubo un notorio cambio en el que el saber occidental se definió casi exclusivamente como alemán. Este 'cambio alemán' + reflejaba cambios más amplios en los niveles más altos del gobierno y, a fin de cuentas, debía ser considerado como el triunfo de la alianza nativista-neo confuciana. Según Buruma "los oligarcas Meiji, a pesar de algunas oposiciones incluso en sus propias filas, escogieron el sendero alemán' porque 'querían ser modernos e invocar tradiciones antiguas al mismo tiempo. Esto se consiguió al aplicar dogmas alemanes a mitos japoneses.”29 Naturalmente, este giro alemán tuvo profundo impacto en la educación. En 1885 el primer ministro de educación, el carismático Mori Arinori, creó una red educacional unificada, basada en el modelo prusiano. Aparentemente Arinori había sucumbido a la presión conservadora, a pesar de haber apoyado abiertamente a los modelos americanos más liberales en la década anterior. ${ }^{30}$ En 1886 se decretó una serie de regulaciones escolares más estrictas y uniformes, todas basadas en modelos alemanes. El apoyo gubernamental a los estudiantes que iban al extranjero empezó a beneficiar 
a aquellos que estudiaban en Alemania y los oyatoi gaijin invitados por el gobierno japonés reemplazaron de manera creciente a sus contrapartes estadounidenses, británicas y francesas. Quizá en ningún otro lado se notó tanto la influencia alemana como en la Universidad Imperial de Tokio, que en un principio basó su modelo en las universidades alemanas y luego dio cargos a docenas de profesores alemanes. ${ }^{31} \mathrm{El}$ idealismo neo kantiano dominaba y estudiar filosofía significaba estudiar el pensamiento alemán. Uno de los profesores alemanes de la Universidad Imperial de Tokio, Emil Hausknecht, se dio cuenta que sus charlas sobre la metodología de enseñanza de Herbart eran cada vez mejor recibidas, en este marco más amplio de re orientación hacia los modelos alemanes. De hecho, el clima político fomentó una 'época dorada de herbartianismo', que haría triunfar a la metodología de los 5 pasos de Herbart a lo largo de Japón durante la década siguiente y más allá. ${ }^{32}$

No obstante, la poderosa alianza nativista - neo confucianista no se aplacaría tan fácilmente, insatisfecha con el modelo alemán, más conservador. El mismo día que se promulgó la Constitución Meiji en 1889, el alguna vez directo y liberal Mori Arinori ${ }^{33}$ fue apuñalado por un fanático nativista, furioso ante una supuesta falta de respeto simbólica de Mori a uno de los santuarios Shintō más sagrados. Sin embargo, el asesinato del ministro de educación tenía motivos mucho más profundos: venía a simbolizar la muerte del modelo liberal en manos de las resurgentes fuerzas nativistas. A continuación siguió el notable Re escrito Imperial sobre Educación (1890), junto con el Reglamento de Escuelas Primarias (1890) y la Explicación de Asuntos Escolares (1891), todos documentos que elevaban la enseñanza moral, la reverencia ante el Emperador y el nacionalismo como metas primarias del sistema escolar. Los modelos alemanes permanecerían en forma, aunque cada vez más reelaborados 'desde adentro', de acuerdo con la lógica de las fuerzas conservadoras. En medio de este cambio conservador, los debates sobre alternativas serían sofocados con creciente fuerza, haciendo difícil que se escuchara voces más liberales, lo que incluiría a la voz distintiva de John Dewey.

De todas maneras no debemos precipitarnos. Aunque se desacreditó la pedagogía herbartiana y el movimiento de la 'nueva educación' empezó a cobrar fuerza, lejos el tema más central de Japón en aquel momento era el surgimiento del nacionalismo y el concomitante desarrollo del orden social que ocurría al son de la modernización comprimida y la movilización militar del país. Mientras Japón luchaba y derrotaba a China en la Guerra Sino-Japonesa (1894-1895) y luego anunciaba triunfante su presencia en el escenario mundial con una victoria aplastante sobre Rusia en la Guerra Ruso-Japonesa (1904-1905), la movilización militar parecía crear un sentimiento de descontento entre el pueblo: decenas de miles de protestantes salieron para manifestarse contra los términos del Tratado de Portsmouth, hecho que terminó en dos días de caóticos disturbios en toda la ciudad. Este evento dio inicio a lo que algunos historiadores han llamado la 'era de la violencia popular', que vio pasar gran cantidad de protestas cada vez más violentas durante la década siguiente. Para la oligarquía tradicional-alemana, esta era la prueba del decaimiento moral que trajo la modernización, mientras que para los desposeídos, aquellos sin derecho a voto y los liberales intelectuales, era la prueba de que la 'iluminación de lo alto' no podía 
satisfacer las necesidades de una sociedad en cambio vertiginoso. Era esta lucha central, la continuación de tradiciones intelectuales inamovibles, la que cumplía nuevos roles a medida que llegaban a Japón las noticias sobre la $1^{\text {a }}$ Guerra Mundial y era en esta receta de nacionalismo y descontento sazonada con incertidumbre esperanzada que John Dewey llegaría a Japón.

\section{Primera Guerra Mundial hasta fines de 1920: La recepción de Dewey en el contexto japonés cada vez más polarizado pero esperanzado}

La $1^{\text {a }}$ Guerra Mundial trajo una prosperidad sin precedentes a Japón; aceleró la industrialización y, por ende, la urbanización, lo que tensionó las contradicciones del gobierno Meiji hasta llegar al punto de quiebre. La espiral inflacionaria en tiempos de guerra tuvo su clímax en los Disturbios por el Arroz, en el verano de 1918, en que miles de granjeros desconformes y una creciente clase obrera urbana desataron una ola de protestas, saqueos y violencia por todo Japón, lo que señaló que eran necesarios cambios fundamentales para mantener el orden público. En respuesta a este nuevo ambiente democrático, el Primer Ministro Teruchi dimitió y en su lugar Hara Takashi se convirtió en el primer plebeyo a cargo del puesto más importante elegido en Japón. Esto se aclamó como un triunfo para la democracia, el primer cambio tangible de un nuevo orden desde que el debilitado Emperador entregara el poder a la Cámara, varios años antes. Las manifestaciones callejeras de 1919 y 1920 continuaron con el fermento iniciado por los intelectuales urbanos, la participación crecientemente enérgica y organizada del proletariado y una proliferación de grupos democráticos, socialistas, comunistas y anarquistas. Cuando terminó la Guerra, con la sumisión de Alemania (referente social japonés por excelencia), las ideas democráticas y liberales de los triunfantes poderes demócratas se convirtieron en el tema de conversación de los círculos intelectuales japoneses. Feuer ${ }^{34}$ relata: "La derrota de Alemania pareció mostrar a los liberales japoneses su oportunidad de atraer a su país lejos de la admiración por los intereses alemanes, políticos e intelectuales, para llevarlos a la teoría y la práctica del liberalismo según el modelo estadounidense.”

En un principio estas mejoras políticas parecían tener grandes implicancias en la educación. Este impulso inyectó vida y una promesa renovada en el movimiento de la 'nueva educación' que se había iniciado silenciosamente hacía una década. Con raíces nacidas de una reacción de pedagogos desencantados contra la pedagogía herbartiana, el progresivo movimiento educativo que había empezado lenta y tentativamente antes de la Primera Guerra Mundial, explotó rápidamente en muchas direcciones diferentes en la atmósfera de posguerra, frenética y liberal. La 'nueva educación' empezó a tomar los colores y el tono de la ideología política que la sustentaba, donde nombres como 'educación liberal', 'educación proletaria', 'la vida en la educación' y 'movimiento literario creativo' conseguían adeptos. El Sindicato Japonés de Profesores Asociación para la Ilustración, creado en 1919, hizo un apasionado llamado a la educación alineada con un espíritu democrático, fundada en el desarrollo del individuo por sobre las necesidades del Estado. ${ }^{35}$ Incluso el gobierno no pudo hacer otra cosa que responder 
a las nuevas demandas en torno a la educación y en 1917 tomo la inédita medida de lanzar el Consejo extraordinario para la educación.

En este entorno, John Dewey llegó a Yokohama el 9 de febrero de 1919. En una recepción poco auspiciosa, Hoashi Riichiro, un emergente y joven miembro del Grupo Waseda de pragmáticos, llegó con entusiasmo al puerto para recibir a Dewey. Sin embargo, al no encontrar ningún hombre que calzara con su idea de un filósofo mayor y distinguido, volvió a casa decepcionado, para enterarse a través del periódico que un hombre joven con el que se había topado ese día resultaba ser Dewey. ${ }^{36}$ Dos acaudalados negociantes japoneses que conocieron a Dewey en Nueva York financiaron el viaje. Dewey y su esposa, Alice, se alojaron en el Hotel Imperial durante las primeras noches pero al sentirse incómodos allí se mudaron al espacioso hogar de Inazō Nitobe, un escritor japonés reconocido en occidente por haber publicado Bushidō: El Alma de la Nació. ${ }^{37}$ Según todos los registros, sus anfitriones japoneses concedieron a Dewey todos los lujos durante su estadía: un pase ilimitado en primera clase en los trenes japoneses, un automóvil privado en Kyoto, elección libre de habitaciones en uno de los hoteles más lujosos de Osaka. También se le presentó lo más exclusivo de la cultura japonesa: obras Noh y Kabuki, los famosos templos de Nara y Kyoto y una velada con las famosas Geishas de Gion, donde su presencia no pasó inadvertida. De vuelta en Tokio, se reunió con el Primer Ministro y se le ofreció la Orden del Sol Naciente, la que Dewey, respetuosa y amablemente, rechazó. En realidad, a nivel personal, su recepción en Japón fue magnánima, según su propia descripción en el prefacio de Reconstruction in Philosophy, ${ }^{38}$ una complación de sus presentaciones en Tokio, publicada en $1920 .{ }^{39}$

Dewey inició su visita profesional con un ciclo de ocho exposiciones, realizadas dos veces a la semana a contar de febrero en la prestigiosa facultad de derecho de la Universidad de Tokio. Era el principal escenario académico e intelectual de Japón, pero también el bastión del idealismo alemán. En un principio, más de 700 personas vinieron a escuchar las charlas de Dewey, pero luego de un par de sesiones esa audiencia se redujo a la mitad, muy probablemente debido a que no había un intérprete disponible. ${ }^{40}$ Basta con sólo imaginar la dificultad del público para comprender la complejidad de las ideas de Dewey en una lengua extranjera, en un salón repleto, sin la moderna tecnología acústica del presente. De todas maneras, en otros lugares las presentaciones de Dewey sí contaban con intérpretes, por lo general estudiantes que habían estudiado en el extranjero y estaban familiarizados con el pragmatismo.

Ese fue el caso cuando Dewey dio una serie de conferencias en la Universidad de Waseda, un baluarte del pragmatismo, relacionado desde antes con Dewey, sin mencionar que se trataba del principal rival de la Universidad de Tokio por el título de la institución académica más prestigiosa del país. El Grupo Waseda de pragmáticos liderado por Tanaka Odō (que había sido alumno de un Dewey mucho más joven en la Universidad de Chicago, ver más adelante), era reconocido en los círculos intelectuales de la época y, además de interpretar las conferencias de Dewey, ayudó de manera más general a imbuir a Waseda de un clima intelectual distinto al de la Universidad de Tokio. También miembros del Grupo Waseda eran Sugimori Kojirō y Hoashi Riichrō, quién esperaba a un hombre de mayor edad en el puerto, el día que Dewey 
llegó a Japón. Además de las conferencias de Tokio, Dewey también se aventuró lejos de la capital, con exposiciones en las ciudades de Kobe, Kyoto y Osaka. Había sido un viaje corto (poco más de diez semanas) cuando Dewey y su esposa abordaron un barco hacia China, donde permanecerían durante dos años completos.

\section{Las tres recepciones intelectuales de Dewey: Fuerzas de la tradición, jóvenes radicales y cristianos liberales}

De mayor importancia que los detalles del viaje es la recepción de las ideas de Dewey en Japón. ¿Cómo las interpretó, evaluó y transformó su audiencia japonesa? ¿Cómo interactuaron con las tradiciones del conocimiento preexistente que evolucionaron de la época anterior? Para analizar la recepción de sus conceptos en Japón es necesario elaborar respuestas distintas para tres grupos diferentes en la sociedad japonesa, de polarización rápida, a la que llegó Dewey: las fuerzas establecidas de la tradición, los agitados jóvenes radicales y la facción cristiano liberal.

La recepción de Dewey en los círculos dominantes y establecidos a nivel filosófico e intelectual fue fría, en el mejor de los casos y antagonista, en el peor. Por ejemplo, un miembro prominente de una facultad de la Universidad de Tokio se mostró impávido e incluso deploró las charlas de Dewey: "Si hubiese dado la misma conferencia en japonés, la audiencia se habría quejado." ${ }^{41}$ Otro preguntó, con aparente desdén: “¿Cuál es esta 'filosofía' de la que habla Dewey?”² Estos comentarios eran sólo una muestra de la duda subyacente más amplia sobre la base de las ideas de Dewey e incluso de sus merecimientos para ser consideradas filosofía. Para explicar esto, cabe recordar que la Universidad de Tokio fue construida a semejanza del modelo alemán y su facultad de filosofía había sido cultivada por profesores alemanes y japoneses formados en Alemania. Estudiar filosofía era estudiar el pensamiento alemán. ${ }^{43}$ Por ahí parte la explicación de la fría recepción intelectual a Dewey.

No obstante, como en gran parte de la historia japonesa, sería erróneo considerar este hecho sencillamente como el pensamiento alemán envuelto en formas japonesas;

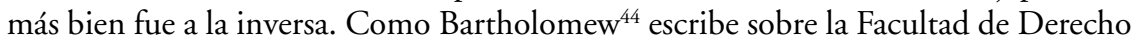
donde Dewey se presentó:

La Facultad de Derecho de la Universidad de Tokio, era particularmente dominada por un elitismo nacionalista y burocrático que la filosofía de Hegel [...] con seguridad debe haber reforzado (si es que no lo originó). Sin embargo, gran parte de lo que se denomina estadista, elitista, autoritario, nacionalista o burocrático en la cultura política o académica japonesa deriva de fuentes más bien nativas que alemanas.

De esta manera nos encontramos con que la historia de Dewey y sus ideas entran en contacto directo con las persistentes tradiciones del conocimiento de Japón. Como las tradiciones indígenas que se mimetizaron en formas alemanas de gobierno, hay bastante evidencia que apoya la afirmación de Bartholomew ${ }^{45}$ de que la filosofía alemana funcionaba de manera similar en la academia japonesa. Kobayashi, ${ }^{46}$ por 
ejemplo, enfatiza la conexión mucho más directa entre la filosofía alemana y estas tradiciones nativas preexistentes cuando discute que el dominio del neo kantismo durante este período

se debía a la preferencia habitual por filosofías subjetivistas, por sobre objetivistas. Debido a su vasta experiencia con el budismo y el confucianismo, ambos tendientes al subjetivismo, los japoneses hallaban menor dificultad en desarrollarse en esa dirección.

De mayor apoyo son los comentarios del principal historiador educacional japonés en cuanto a que "filosofías como la de Dewey son demasiado prácticas, demasiado sencillas como para fascinar a los alemanes o a los japoneses." ${ }^{47}$ En definitiva, la poca apertura ante este pragmatismo se puede considerar como la persistencia de formas indígenas del conocimiento, así como una ventana a la manera en que funcionaba la filosofía alemana como medio de articulación para el conocimiento indígena. Para profundizar en el tema, también podríamos contrastar la recepción de Dewey con la que tuvo Josiah Royce, un estadounidense que mezclaba su idealismo absoluto con nociones de lealtad y que se convirtió en favorito de los filósofos japoneses durante los años previos a la llegada de Dewey. Feuer ${ }^{48}$ explica que "la distancia filosófica entre Royce y Dewey era similar en Japón a la distancia política entre el absolutismo militarista y la democracia liberal. La filosofía de Dewey no estaba cayendo en terreno fértil."

En el otro extremo del espectro político y cultural estaban los grupos cuyas demandas hacían inaceptable la articulación alemana. No obstante, aquí tampoco resonó el mensaje de Dewey, ya que ante los ojos de estos radicales jóvenes no era lo suficientemente consistente como para enfrentar los desafíos que encaraba Japón. Este era el polo opuesto de una sociedad japonesa que se polarizaba rápidamente. Inspirados por la revolución bolchevique y energizados por el proletariado urbano resultante del auge de la industrialización en Japón, los jóvenes radicales no estaban unidos, pero aún así sus ideas revolucionarias de socialismo, comunismo y anarquismo potenciaron el discurso político y emergieron apoyándose mutuamente. Esto hizo que la filosofía y la pedagogía de Dewey, que se negaban a articular un tipo específico de sistema social, levantara algo de sospecha, a pesar de priorizar el proceso democrático:

Muchos de los educacionistas, al igual que otros intelectuales de la época, estaban interesados en el socialismo, al que asociaban con la democracia y la postura de Dewey parecía ambigua, ya que no se inclinaba claramente por ningún tipo de sistema socialístico. ${ }^{49}$

Esto se debía en parte a que muchos marxistas japoneses tendían a relacionar al capitalismo con occidente y, así, se volvieron particularmente críticos de las ideas de occidente y de sus agentes. De acuerdo con lo anterior, algunos veían la filosofía de Dewey como una 'expresión del imperialismo capitalista de Estados Unidos', mientras que otros se enfocaban en al ángulo de las clases sociales, calificando a su filosofía 
como 'una ideología capitalista burguesa'. Para justificar su punto, destacaban el hecho de que la presencia de Dewey sólo era posible gracias a acaudalados negociantes japoneses. ${ }^{50}$ En el ámbito educacional, estos radicales más bien utilizaban como referencia el trabajo de Paul Natorp, cuya mezcla de filosofía neo kantista y pedagogía al estilo socialista, con énfasis en la solidaridad, parecía mucho más aplicable, tanto a las tradiciones como a las realidades de aquel momento en Japón. En 1924, se publicó un popular libro, titulado ¿Natrop or Dewey., ${ }^{51}$ que despejó por completo el debate. El autor, como la gran mayoría de los radicales jóvenes, estuvo a favor de Natrop.

Aunque los indiferentes intelectuales dominantes y los desdeñosos jóvenes radicales representaban las fuerzas más importantes de la sociedad japonesa en aquellos tiempos, había una pequeña 'fracción' progresista en que las ideas de Dewey tuvieron una grata recepción. La mayoría de los miembros de este grupo tenía dos características distintivas: habían estudiado en los Estados Unidos y, en su gran mayoría, se trataba de cristianos protestantes. El perfil de Tanaka Odō, líder del Grupo Waseda de pragmatistas y quizá el seguidor más acérrimo de Dewey, es ilustrativo. El joven Tanaka había recibido el espíritu Meiji de reconstrucción de Japón y el ideal de buscar conocimiento en el extranjero. ${ }^{52}$ Nolte $^{53}$ escribe: "Él admitía la visión integral de los sabios confucianos, pero rechazaba su insistencia en la jerarquía social y despreciaba su prevalente y limitado enfoque utilitario del conocimiento occidental." Se convirtió al cristianismo y aprendió inglés con los misioneros estadounidenses para luego embarcarse a estudiar en Estados Unidos. Se las arregló para llegar a la Universidad de Chicago y estudió bajo la dirección del joven John Dewey entre 1894 y 1897; volvió a Japón y rápidamente consiguió un puesto en Waseda, transformándola en un centro del pragmatismo, que produjo a algunos de los más reconocidos liberales, pragmatistas y seguidores de Dewey: Ueda Seiji, Nieda Rokusaburo, y Hōashi Riichirō. Aunque no tenían filiación institucional con Waseda, otros como Hani Motoko, Obara Kuniyoshi, Nishimoto Mitoji, y Kawasaki Riichi, mostraron una mezcla similar de cristianismo y experiencia en Estados Unidos que parecía originar grandes afinidades con Dewey. Estos personajes no sólo recibirían a Dewey en Japón, sino que además serían los primeros intérpretes de su trabajo, tanto durante los años siguientes a su visita, como también luego de la Segunda Guerra Mundial

Más allá de sus relaciones personales con Dewey y de la formación cristiana compartida, no queda claro de inmediato porque debería haber tanta coincidencia entre este grupo y las ideas de Dewey. Seguramente experimentaban la marginación de la corriente tradicional-alemana imperante, que debe ser un fuerte motivo para que hallaran tal resonancia en la filosofía democrática de Dewey. Quizá también sintieron que el individualismo de principios era la manera de promover los ideales cristianos o quizá simplemente reaccionaban ante la atmósfera política y social crecientemente represiva. Escritos de Hoashi publicados al inicio de los años $20 .{ }^{54}$ apoyan este último punto, como cuando escribió (a pesar de ser censurado por el gobierno) que las universidades sencillamente estaban dando legitimación intelectual al autoritarismo inspirado por Prusia. ${ }^{55}$ Aquí también vemos que un eje de la recepción de Dewey era la lucha sobre que referente social contendría el imaginario de Japón. Esta pequeña fracción progresista, que se convertiría en intérprete de Dewey para Japón y 
favorecería el modelo estadounidense, tendría la poco envidiable misión de revertir cuatro décadas de dominio alemán originado en tradiciones japonesas de raíz nativista y neo confuciana.

\section{Transformación y apropiación en la facción liberal: Algunas interpretaciones japonesas de Dewey}

Para nuestros propósitos es importante comprender como la pedagogía y la filosofía de Dewey fueron interpretadas y transformadas por este selecto grupo que sí defendió estas ideas. Acá nos encontramos con que, a pesar de sus afinidades con Dewey, acomodaron sus ideas de acuerdo con la lógica de la realidad japonesa de diversas formas. Primero, priorizaron al individuo en mucho mayor medida que Dewey, criticando así de manera directa a la atmósfera política de conformismo rígido. En este punto podríamos examinar las ideas de Tanaka, quién probablemente fue el que más trabajó para adaptar las ideas de Dewey de manera que fueran relevantes en el contexto japonés. Nolte, ${ }^{56}$ el estudioso más destacado de Tanaka y, en general, del movimiento Taishō, opina que:

Tanaka acentuó el individualismo aún más que el propio Dewey, quién recalcaba la necesidad de la cooperación y la ingeniería social en un Estados Unidos industrializado. Desde su perspectiva, la primera tarea del movimiento democrático en Japón consistía en lograr la libertad individual en el pensamiento, las leyes y las costumbres.

Debido a la débil base del 'individualismo de principios' en la sociedad japonesa ${ }^{57} \mathrm{y}$ a las necesidades del movimiento democrático del momento, este acento selectivo en aspectos específicos de los pensamientos de Dewey tiene bastante sentido.

Una segunda manera en la que se transformó las ideas de Dewey fue un sutil, pero inconfundible, alejamiento del optimismo y de la pasible inevitabilidad del progreso social encontrado en los discursos y escritos de Dewey. Tanaka sentía que el proceso de evolución social de Dewey estaba lejos de ser inevitable y fácilmente podía ser detenido, alejándolo hacia la 'rigidez de las costumbres' o bloqueado, por 'clases sociales' antagonistas. ${ }^{58}$ Esta era, con claridad, la situación que enfrentaban los liberales japoneses en aquel momento, lo que los hacía incapaces de compartir la apreciación optimista de Dewey sobre los procesos naturales de evolución social. De esta manera se creó una diferencia significativa de tono entre Dewey y sus intérpretes japoneses, quienes a toda costa evitaban caer en la tradición o en el conflicto de clases, por lo que escribían en un tono mucho más definido hacia el activismo social, con frecuencia abogando enérgicamente por el cambio social. Nolte ${ }^{59}$ afirma este punto en relación con los escritos de Tanaka, sugiriendo que aquellos trabajos "diferían de los de Dewey, principalmente en su tono exhortativo, que implicaba que el acento en el aspecto individual tenía menor relación con la conveniencia intelectual que con la relevancia de los problemas sociales."

En tercer lugar, hay amplia evidencia que demuestra que las ideas de Dewey sobre 
la educación, una vez adaptadas al contexto japonés, se desconectaban de la lógica subyacente al pragmatismo. Esto pudo haber sucedido tanto debido a la inhabilidad de los educadores para comprender la complejidad de las ideas de Dewey (en especial cuando no mediaban los intérpretes) como debido al ambiente político represivo. Kobayashi ${ }^{60}$ toma este último punto:

los educacionalistas progresistas estaban limitados por la estricta vigilancia gubernamental sobre sus actividades; el currículo escolar en sí estaba bajo estricto control del gobierno [...] de manera consecuente, se mostraba poco interés en las profundas bases filosóficas de las ideas educacionales de Dewey; muy pocos comprendían el pragmatismo.

Otra posibilidad es que la pedagogía de Dewey fuera separada intencionalmente de sus raíces pragmáticas por educadores e intelectuales que de verdad deseaban mejorar la educación, pero no por el bien de los individuos, sino que por el bien de la nación. Es importante no subestimar el nivel de exposición de Japón al nacionalismo en aquellos tiempos. Más allá del simple resultado de los esfuerzos para instigar el nacionalismo como parte del proyecto más amplio de modernización, la repetida discriminación contra Japón en la comunidad internacional (muchos citan el fracaso de la Liga de las Naciones en su intento por incluir una cláusula de igualdad racial), motivó a muchos educadores y pensadores progresistas a considerar la pedagogía de Dewey no como un fin en y por sí misma, sino como una manera de fortalecer a la nación. En este pinto encontramos que "mucho del entusiasmo por nuevas técnicas pedagógicas que defendían los progresistas también se hallaba en el marco de los objetivos nacionalistas de educación. Para muchos profesores, los métodos progresistas significaban una mejor enseñanza, para el bien de la nación." ${ }^{61}$ Esta inversión de Dewey se puede atribuir al clima político, pero igualmente a las formas en que estas ideas nacionalistas encontraban eco en las tradiciones indígenas y la historia de Japón. Esto incluso se hace más evidente en los intelectuales que se identificaron abiertamente con el pragmatismo y, aún así, lo alteraron para que coincidiera con la situación japonesa. Ohkura ${ }^{62}$ apoya este punto con el caso de Oikawa Heiji, uno de los educadores progresistas más conocidos de la época, quién defendía la “incorporación del concepto pragmático de autogobierno para reflejar la vida en términos de autorregulación colectiva. Su principal argumento era que el autogobierno del liberalismo era compatible con la necesidad de control social mediante el uso de una forma de pedagogía orientada a la resolución de problemas."

En los años que siguieron a la visita de Dewey, las principales características del escenario social, intelectual y educacional de Japón persistieron casi igual que antes. La inestabilidad continuó con el asesinato del Primer Ministro Hara en 1921. Igualmente, el control del gobierno continuó y se fortaleció: Hoashi Riichiro fue encarcelado durante dos meses y su libro sobre ética prohibido, ya que no hacía referencia a la familia imperial. Los jóvenes radicales continuaron con la agitación, aunque cada vez más decepcionada su esperanza de democracia. El 22 de julio de 1922, se conformó el Partido Comunista de Japón (con la ayuda del brazo operativo 
de ComIntern fuera de Moscú), engrosando sus filas rápidamente hasta que las leyes de Preservación de la Paz, dispersaron a sus miembros y los confinaron al anonimato. El movimiento de educación progresista también tuvo auge durante un tiempo, hasta que enfrentó la misma suerte. Guiadas por visitas de Helen Parkhurst quién presentó su 'Método Dalton', en 1924, y William Heard Kilpatrick, quién prmovía su 'Método Proyecto', en 1927, las escuelas progresistas siguieron proliferando, con nombres como 'Freedom Hills School' (Jiyu-gaoka). Los libros sobre Dewey se vendían bien, pero aún así sería mucho decir que Dewey realmente había dejado una huella, siquiera en el movimiento progresista de educación, sin otro motivo que lo reducido de este movimiento en Japón. Un par de escuelas normales (especialmente una en Nara) implementaron nuevos enfoques, según ellos inspirados por Dewey, pero estos parecían tener menor relación con su visita al país que con la legitimidad que proporcionaba su reputación internacional. De hecho, a fin de cuentas la visita de Dewey debe ser considerada como insignificante en su momento. Su significación solo creció luego de la Segunda Guerra Mundial, debido a esa reducida facción liberal que terminó siendo 'el último superviviente' de estos tres grupos que dominaron la era Taishō.

\section{La marcha hacia la Segunda Guerra Mundial: Eliminando a la oposición (progresista)}

Japón marchaba hacia la Segunda Guerra Mundial al son de los tradicionalistas encubiertos en formas alemanas, eliminando en primer lugar a los radicales jóvenes, para luego dirigir la atención hacia los liberales y su movimiento de educación progresista. La democracia Taishō, nunca tan saludable como los historiadores de épocas posteriores quisieran creer debido a las tensiones internas, ${ }^{63}$ se empezó a sofocar bajo las sucesivas y cada vez más estrictas leyes de Preservación de la Paz $(1926,1928)$, mientras que una vigilancia cada vez más intrusiva del aparato de vigilancia estatal ahogaba de manera activa las críticas izquierdistas. Por el año 1929, el partido comunista había sido confinado por completo al anonimato y, según la mayoría de las versiones, para 1933 ya había dejado de existir en gran parte. Esta ausencia de oposición, avivada por las crecientes tensiones internacionales y la depresión económica, concedió a la cada vez más conservadora y nacionalista tendencia principal la ventaja para trazar los destinos a futuro. Buruma ${ }^{64}$ destaca tanto la continuidad histórica como las dimensiones internacionales, cuando escribe: "Era como si el monstruo militarista, forjado hacia el final del período Meiji a partir de una mezcla entre Edo nativismo tardío y teorías raciales tomadas de los alemanes, hubiera finalmente dado origen a una horrible forma de vida." Este 'monstruo militarista' se dirigiría a invadir Manchuria en 1932, China en 1937 y Estados Unidos en 1941, guiado por los mitos principales de la escuela nativista (un emperador divino, el shintoismo y el excepcionalismo japonés), además de los ideales neo confucianos (un estado fuerte, relaciones sociales rígidas y 'virtudes' acordes con el militarismo, como la lealtad).

Durante más de una década, a medida que los militares se afianzaban en el poder, el movimiento educativo progresista avanzaba con dificultad, aunque era 
constantemente reprimido. Ya en 1924, el ministro de educación había enviado una enérgica advertencia sobre las consecuencias del inconformismo en las escuelas. En 1926, el entrenamiento militar se volvió obligatorio, en las escuelas públicas y privadas. Enfrentados a la presión creciente, la tendencia de más y más educadores progresistas fue la de ubicar esta línea educativa en el marco más amplio del bien de la nación. La Conferencia de la Fraternidad Mundial para la Nueva Educación llegó a Tokio en 1932 para legitimar las ideas progresistas y el pragmatismo reminiscente de Dewey hasta cierto punto, aunque quizá era demasiado tarde. De mucha más influencia fue el notable kokutai no hongi del gobierno, promulgado en 1937 (Declaración de Principios de la Entidad Nacional de Japón), al que siguió la designación del general Araki Sadao como ministro de educación en 1938, lo que elevó las doctrinas nativistas-ultra nacionalistas y militaristas a la condición de filosofía educacional oficial.

Este cambiante contexto político nuevamente tenía profundas implicancias para lo que se consideraba como saber (filosófico, educacional u otro) y, por ende, para las ideas de Dewey en el contexto japonés. A pesar del publicitado esfuerzo gubernamental para limpiar a Japón de la influencia 'occidental', hecho más evidente al traducir los préstamos léxicos occidentales como palabras japonesas (como la traducción de baseball por yakyu, el ideograma chino equivalente) y eliminar a figuras estadounidenses y británicas como Benjamin Franklin y Florence Nightingale de los cursos de moral, ${ }^{65}$ la filosofía alemana continuó prosperando: "Aunque durante la Segunda Guerra Mundial se desincentivó y llegó a prohibir la investigación sobre filosofías occidentales, hubo excepciones para el estudio de filosofías alemanas que estuvieran en línea con la ideología oficial." ${ }^{66}$ Más adelante esto revela la intrincada relación entre las ideas nativistas y las formas alemanas que las legitimaban. En cuanto a Dewey, no existía el nivel de 'degradación' que se podría esperar y había poca evidencia de represión u orientación específica hacia sus pensamientos. De manera un tanto paradójica, este hecho presenta parte de la mejor evidencia de que las ideas de Dewey y el movimiento de educación progresista liberal no eran una amenaza para las poderosas fuerzas ideológicas de la corriente principal y en vez de ser suprimidas de manera activa, se habían disipado en gran parte de manera espontánea, de acuerdo con la gran oleada de ultranacionalismo. Ya en 1944, por ejemplo, aún era posible publicar un libro sobre Dewey, aunque sería uno con un vuelco en el mensaje, ya que utilizaba las palabras del mismo Dewey para criticar el 'carácter nacional estadounidense. ${ }^{67}$

También contribuía a la declinación de la oposición progresista el proceso más natural de envejecimiento y muerte de varios miembros del movimiento liberal que habían alcanzado la madurez durante la primera década liberal luego de la Restauración Meiji, quienes habían permanecido durante el turno alemán y luego habían reafirmado sus voces durante el período de Democracia Taishō. Tanaka Odō, por ejemplo, murió en 1932. Yoshino Sakuzō (quizá el rostro más conocido de la Democracia Taishō) murió en $1933 .{ }^{68}$ Los discípulos de esta primera generación liberal habrían alcanzado su madurez durante el camino a la Segunda Guerra Mundial, pero en vez de eso, debieron esperar hasta la rendición incondicional de Japón en 1945 y las subsecuentes limpiezas para encontrar espacio para sus ideas. 


\section{Auge de Dewey en la posguerra: Liberales abandonados y renacimiento de la 'tradición'}

Desde este punto podemos volver a desentrañar el 'auge' de Dewey, destacado al inicio. De hecho, una vez expuesto el contexto histórico, político e ideológico de la visita de Dewey a Japón, se puede apreciar el repentino brote de entusiasmo por sus ideas como algo de lo más extraordinario. Asimismo, el descarnado contraste entre la recepción personal de Dewey y su nueva recepción luego de la Segunda Guerra Mundial, revela claramente la dinámica en que el cambio político e ideológico conduce a ajustes profundos en las definiciones sobre lo que constituye saber educacional. Durante este tiempo, no sólo ocurrió una fascinante reinterpretación de la influencia de Dewey que llevó el impacto de su visita a una proporción mucho más allá de su significado actual, sino que, de manera crucial, los eventos de este período transformaron a Dewey en una herramienta retórica y simbólica dentro de los debates sobre educación en Japón.

Luego de la rendición incondicional de Japón en 1945, los cambios en el escenario político, ideológico y cultural eran tan profundos y de gran alcance como cualquier otro momento en la historia del país, cambios repentinos con pocos paralelos aparentes en el mundo ${ }^{69}$ Un doloroso ejemplo es que el Emperador, quién había sido elevado a la categoría de dios viviente durante gran parte de la década anterior, rompió el precedente de silencio imperial, anunció la rendición de Japón y luego anunció la renuncia a su propia divinidad. La ocupación de los aliados sería principalmente un asunto manejado por Estados Unidos y los cambios en la estructura política y social japonesa serían rápidos y decisivos: se adoptó una nueva Constitución en noviembre de 1946, orientada a eliminar las influencias autoritarias y reconstruir (o revigorizar, dependiendo de la noción previa que se tenga de Japón) las instituciones democráticas. Las autoridades de la ocupación identificaron a la educación como una fuente principal que impulsó a Japón a la guerra, así como uno de los mecanismos primarios para reconstruir una sociedad japonesa más democrática. En 1947 se promulgó la Ley Fundamental de Educación, la que garantizaba espacio para el individualismo y prohibía de manera explícita el uso de la enseñanza para objetivos nacionalistas. Los principales temas propuestos por la Misión de Educación de Estados Unidos, que visitó Japón en 1946, eran la desmilitarización, la democratización y las descentralización, recomendaciones tomadas claramente del sistema estadounidense, hecho que originaría problemas y condimentaría los debates locales sobre políticas educativas durante décadas. ${ }^{70}$

Parece haber un debate académico anterior en cuanto a hasta que punto las ideas de Dewey era una política explícita de las autoridades de la ocupación, con importantes implicaciones para la exploración del 'auge' de Dewey. Saito e Imai, ${ }^{71}$ citando fuentes secundarias en japonés, apuntan que "efectivamente, el pensamiento educacional de la misión estaba influenciado por la filosofía de la educación progresista de Dewey, al igual que por el idealismo del Nuevo Pacto estadounidense." Estos autores indican que la misión incluía a George S. Counts, "un discípulo de la filosofía educativa de Dewey." Tsuchimochi ${ }^{72}$ también informa que el nombre de Dewey había 
sido presentado como candidato para integrar esta Misión, aunque esto jamás se materializó. En contraste, Kobayashi, ${ }^{73}$ al llevar a cabo entrevistas personales con los ex miembros de la Misión a inicios de la década de 1960, no encontró usos explícitos de Dewey en las políticas definitivas. A la larga, la conclusión de Kobayashi parece ser más plausible, debido a sus fuentes y a que Saito e Imai no toman en cuenta la reinterpretación de los períodos históricos hecha por estudiosos interesados en promover a Dewey, un tema central de este análisis. De esta manera, en vez de rastrear el 'auge' de Dewey entre los dirigentes de la Ocupación Aliada, debemos buscar explicaciones más elaboradas para la urgencia por glorificar a Dewey.

De hecho, un análisis más contextual, basado en la historia, parte por examinar los drásticos cambios en el paisaje político durante los primeros meses que siguieron a la rendición: las autoridades de la ocupación no sólo despejaron de políticos y burócratas militaristas, sino también de varios miles de profesores militantes. La limpieza se extendió al plano universitario, donde también hubo despidos de profesores (especialmente aquellos que promovieron el kokutai de manera más activa). La facultad que enseñaba filosofía alemana era particularmente sospechosa. Este era un esfuerzo directo y concertado de la ocupación para atraer la orientación intelectual de Japón lejos de Alemania y se debe analizar como la remoción de la mayor fuerza opositora a los liberales. ${ }^{74}$ En el otro extremo del espectro político, las autoridades de la ocupación también removieron activamente a la izquierda radical, aunque no de manera inmediata. De hecho, en un inicio la ocupación avaló concientemente a esta facción como una expresión de contrapeso ante los tradicionalistas. ${ }^{75}$ Un ejemplo significativo es el apoyo del general MacArthur a la formación del Sindicato de Profesores de Japón, organizado principalmente por los herederos socialistas y comunistas de los radicales jóvenes.

Pero esta realidad duró poco. Ya en 1949 se pudo apreciar un 'vuelco' a medida que las tensiones políticas matizadas por la Amenaza Roja en los Estados Unidos y la guerra en Korea cambiaban el enfoque norteamericano en cuanto a la ocupación. Se prohibía las huelgas, se reprimía a los sindicatos y la izquierda también se volvió sospechosa: "el celo reformador de los Estados Unidos se había aplacado y el ambiente en Japón sufrió un cambio importante." 76 El efecto fue que la limpieza inicial de conservadores se replicó, esta vez orientada a la izquierda 'radical'. Aunque algunos conservadores se las arreglaron para recobrar puestos de poder mientras la atención se iba con la 'amenaza' comunista, ambos bandos fueron debilitados de manera considerable, por lo menos hasta 1953. Con un nuevo énfasis en la democracia, la 'fracción' progresista y liberal era el último actor aceptable en el escenario político e intelectual japonés, un actor dispuesto a representar el papel que las autoridades estadounidenses esperaban que cumpliera.

De esta manera, en vista del consecuente vacío político, los liberales emergieron con libertad para promover su visión del mundo, reinterpretar la historia y publicar su visión de la educación y sobre todo lo que había salido 'mal' durante las dos décadas anteriores, por lo menos hasta que las fuerzas neo confucianas y nativistas fueron capaces de rearmarse una vez que terminó la ocupación. Los liberales hicieron esto mediante innumerables métodos, pero de manera más notable (e importante en este contexto) mediante una redefinición del movimiento Taishō por la educación 
progresiva y del lugar que le correspondía allí a Dewey. Repentinamente, estudiosos de Dewey que no tenían formas de difundir su trabajo durante la década anterior, se encontraron sin obstáculos para publicar sus ideas en el nuevo clima fomentado por la ocupación. Según relata Kobayashi, ${ }^{77}$ Nagano Yoshio, un prominente estudioso de Dewey en la posguerra, acotaba lo siguiente:

con la llegada de la Segunda Guerra Mundial, se hizo imposible publicarlos [artículos sobre Dewey], de manera que sus manuscritos estaban escondidos en el subterráneo para protegerlos del bombardeo sobre Tokio. Se publicaron con rapidez a continuación de la guerra y entregaban un importante registro sobre la profusión de libros acerca de Dewey durante los años de la ocupación estadounidense.

Más aún, el flujo de estudiantes que asumía cargos en los departamentos de educación y escuelas normales, originados por las limpiezas luego de la guerra, estaba deseoso de estudiar a Dewey como una manera de entender, sino lograr el beneplácito de las autoridades. De hecho, hubo un intenso interés entre muchos japoneses por comprender el pensamiento estadounidense y, por extensión, a estas autoridades, donde organizaciones como la Sociedad por la Ciencia del Pensamiento y el Seminario por la Investigación Americana germinaron rápidamente. Con este clima político, Dewey fue considerado como el filósofo y educador estadounidense por excelencia.

En juego están también fuerzas diferentes, aunque relacionadas: el deseo de muchos japoneses de demostrar a las autoridades de la ocupación que Japón sí tenía una tradición democrática. Esta es la reinterpretación más amplia de la historia de preguerra y que confiere nuevo significado a la visita de Dewey a Japón. Apareció una gran cantidad de trabajos que elevaron al movimiento democrático Taishō de una manera muy desproporcionada respecto de su verdadero impacto. Algunos, como Shibata Shingō, un respetado filósofo e historiador social del momento, llegaban tan lejos como para proclamar que el pragmatismo era "la filosofía del movimiento democrático Taishō," 78 lo cual necesariamente perfilaba la visita de Dewey como un estímulo para un movimiento filosófico y social completamente original que (supuestamente) arrasó en Japón. No sólo hay poca evidencia que respalde esta afirmación como se ha intentado mostrar, sino que toda la conceptualización está inherentemente parcializada, debido a que exagera el impacto y el espectro del movimiento democrático Taishō en sí. Sin embargo, eran estos tipos de reinterpretación los que aparecían con frecuencia y venían a catalizar de manera directa el 'auge' de posguerra de Dewey. Aquí, nuevamente, la contribución de Kobayashi ${ }^{79}$ es la más adecuada: "Dewey no era sino uno de los muchos pensadores de Europa y América que inspiraron a los progresistas japoneses [durante el período Taishō]; no obstante, en los años que siguieron a la Segunda Guerra Mundial, los japoneses tendieron a identificar al movimiento progresista como un movimiento de Dewey."

Este giro dirige la atención a la siguiente etapa del 'auge' de Dewey. Incluso antes del fin oficial de la ocupación, el 'vuelco' junto con varias declaraciones de las autoridades de la ocupación, habían señalado de manera implícita cierta tolerancia ante 
el resurgimiento de la alianza tradicional, dada la alternativa socialista (percibida). Beauchamp ${ }^{80}$ describe la manera en que este hecho tuvo efectos inmediatos en la educación a inicios de la década de 1950 :

El Primer Ministro Shigeru Yoshida defendía la creación de una declaración educacional sobre la moralidad, que reemplazara el Reescrito Imperial. Al año siguiente, Teiyu Amano, por entonces ministro de educación, motivó acusaciones sobre el renacimiento del militarismo, al proponer la celebración de las fiestas patrias izando la bandera del sol naciente e interpretando el himno nacional. También apoyó la petición de Yoshida sobre un nuevo código ético que reemplazara al desacreditado Reescrito Imperial.

Este énfasis en la moralidad revela las conexiones con la herencia neo confuciana de Japón, mientras que los símbolos de la bandera del sol naciente y el himno nacional sugieren la reafirmación de las ideas nativistas-nacionalistas. Intuyendo esto y temiendo un nuevo desenlace militarista, la reacción de los progresistas no tardó. Hubo 'movimientos por la educación del pueblo' lanzados por el Sindicato de Profesores de Japón, los que "involucraron a muchos filósofos de la educación y pedagogos, desde el bando liberal hasta la izquierda marxista." ${ }^{81}$ A partir de este punto, las referencias a Dewey se vuelven, sutil pero notablemente, imbuidas por todo un nuevo significado: un símbolo de protesta contra los ascendentes tradicionalistas y el fantasma del retorno al exceso conservador de preguerra. Esta interpretación nos permite explicar porqué la cantidad de traducciones y trabajos sobre Dewey, festivales y otras manifestaciones entorno a su figura se extienden hasta mucho después de terminada la ocupación e incluso alcanza su punto álgido luego de que esta termina. Para tomar sólo un ejemplo ilustrativo de este punto, la formación de la Sociedad Dewey en Japón ocurre en 1957. A pesar del interés previo y sostenido del mundo académico por Dewey, la formación del grupo no ocurre durante la ocupación, sino que en medio de la reversión de muchas de las reformas democráticas implementadas por la ocupación, como la eliminación de las juntas escolares locales democráticas (1955) y la reintroducción de los cursos de educación moral (1958).

Así, luego del 'auge' de Dewey, nos encontramos con que éste pasa de ser un filósofo, pragmático y defensor del la educación progresista estadounidense a ser un símbolo de protesta que encapsula (1) una elevación del significado del movimiento demócrata Taishō, (2) las reformas democráticas 'perdidas del período inmediato de ocupación y (3) una protesta contra las tradiciones neo confucianas y nativistas resurgentes y, por ende, (4) una crítica a la emergente 'regresión' del status-quo en las instituciones políticas y educacionales japonesas. Al igual que en la era Meiji, cuando a los modelos y las instituciones alemanas se les inyectó sentido japonés hasta que se mantuvieron en muy buena forma por sí mismas, en el período a continuación de la Segunda Guerra Mundial, el nombre 'Dewey' se reinventa de maneras que generaron una asociación con las realidades de Japón aún más fuerte que la de las ideas originales de John Dewey. En vez de que Dewey cambiara Japón, nos encontramos con que quienes lo 'adoptaron' alteraron 'sus ideas' de manera que estas, en última instancia, 
reflejan las relaciones dentro de las tradiciones de saber preexistentes $y$ del cambio político que ocurría en Japón. Claramente, esto dista mucho de una promulgación japonesa ${ }^{82}$ de sus famosos ideales democráticos y progresistas. Como tal, se hace cada vez más complicado argumentar y, para que decir, rastrear, el impacto de Dewey en el contexto japonés, debido a que las referencias sobre él tienen más relación con el contexto político e ideológico en el que se enmarcan que con las ideas en sí.

\section{Década de 1960 hasta el presente: Continuidad, re polarización y desaparición de Dewey}

Para el inicio de los años sesenta, el 'auge' de Dewey había decaído en gran parte. El famoso plan de aumento del salario al doble del Primer Ministro Ikeda, anunciado en 1960, iniciaba una nueva época de crecimiento económico. Sin dudas la economía japonesa crecía a un ritmo frenético, fomentando la rápida migración del campo a la ciudad a medida que se expandían las posibilidades de empleo aumentaba la movilidad social..$^{83}$ Estos factores, aparejados con el hecho de que la generación nacida del aumento de la natalidad en la posguerra estaba empezando su educación secundaria, llevó a crear políticas enfocadas primeramente en la expansión educacional focalizada que gozaba de amplio consenso político. Se incrementó el número de escuelas técnicas y se trazaron planes para la preparación de una gran cantidad de científicos e ingenieros. Este simultáneo fortalecimiento de ciertos sectores junto con la repentina llegada a la secundaria de los nacidos en posguerra llevó a una intensa competencia y demanda sobre la educación. Sus efectos (como la persistente imagen del 'infierno de los exámenes') parecería ser cualquier cosa menos la educación democrática que proyectaban Dewey o las autoridades de la ocupación. No obstante, según explica Beauchamp:

No era tanto que los ideales democráticos de la ocupación hubieran pasado al olvido (cosa que el segmento más democrático de la población permitiría), sino que luego de años de dificultades económicas había un consenso mayoritario sobre la necesidad de reconstrucción económica. La política educacional durante los años sesenta y gran parte de los setenta estaba concientemente orientada a fomentar el desarrollo económico. ${ }^{84}$

Una de las principales maneras en que el 'segmento más democrático de la población' no permitiría que la memoria (o la esperanza) de la democratización se desvaneciera sería, nuevamente, utilizando a John Dewey de manera simbólica, donde los educadores y académicos liberales continuarían publicando obras sobre él, ${ }^{85}$ a menudo utilizando sus ideas como una manera de demostrar cuánto se había alejado Japón de sus 'raíces democráticas'

Sin embargo, una polarización que crecía sutilmente, añorante del período Taishō, nuevamente encontró a los liberales que promovían a Dewey cada vez más marginados. Según describen Saito e Imai ${ }^{86}$ durante este tiempo, las ideas de Dewey eran "criticadas no sólo por los conservadores, sino también por los marxistas y otros que 
estudiaban la pedagogía soviética, debido a su 'anti-intelectualismo' y su 'empirismo de obrar sin objetivos." Para los tradicionalistas y los conservadores, "la educación de Dewey, centrada en el alumno y orientada a la resolución de problemas, era susceptible de crítica debido a la preocupación acerca de la decadencia de la moralidad y del dudoso desempeño académico de los alumnos." ${ }^{87}$ Entre los estudiantes y los intelectuales de izquierda cuya militancia aumentó (incluso llegaron a tomarse la Universidad de Tokio durante más de un año en el marco de las violentas protestas de 1968) y los conservadores de derecha que se negaban a ceder terreno, los liberales vieron sus voces ahogadas o simplemente ignoradas, de manera muy similar a lo que ocurrió durante la era Taishō. Los estudios y las referencias a Dewey se fueron desvaneciendo (si es que no desaparecieron) bajo el reinado de la academia. Haciéndose eco de muchos que han evaluado la influencia de Dewey históricamente ${ }^{88}$ lamentan la pérdida de entusiasmo por Dewey en las décadas posteriores a la de 1950: "Dewey había ido y venido, como una moda pasajera: su pensamiento no había germinado en el suelo de la cultura japonesa."

Esto nos lleva a una reflexión final sobre el lugar de Dewey en el panorama educacional del Japón actual. Lo que resulta fascinante, aunque no sorprende, considerando la historia reconstruida aquí, es que aún encontramos los mismos marcos del debate, la misma batalla vigente entre las tradiciones auto evolutivas del saber. La tensión neo confuciana se aprecia con claridad en la respuesta social ante el (supuesto) incremento en la violencia escolar y los disturbios de los años ochenta y noventa. Beauchamp ${ }^{89}$ hace la conexión, citando a un prominente educacionalista japonés: "Las acciones de este grupo aún minoritario han impactado al Japón adulto, ya que 'su comportamiento viola el código más fundamental de los valores educativos tradicionales de línea confuciana, a saber, el respeto y la obediencia a los maestros." También se aprecia la perdurabilidad de los valores neo confucianos en repetidos intentos de implementar formas particulares de educación moral, como la iniciativa más reciente, llamada Educación del Corazón (1997). Los nativistas también están vigentes y en buen pie. Marshall $^{90}$ informa que en particular durante la década de 1980, cuando occidente empezó a mirar hacia Japón, buscando su 'receta secreta' para el éxito educacional llevado al plano económico, se fortaleció el discurso nativista:

De manera creciente durante la década de 1980, las ideas sobre tal exclusividad cobraron popularidad entre la prensa y otros medios. El debate tenía una nueva etiqueta (Nihonjinron o 'discurso sobre la identidad japonesa') pero era esencialmente una versión revitalizada de las luchas ideológicas de preguerra y sucesora de la tradición nativista del siglo XIX.

En hechos más recientes, el ex Primer Ministro Abe Shinzō (2006-2007) promovió activamente una línea nativista-nacionalista similar, que llevó a un movimiento con nexos a las principales organizaciones religiosas Shintō, que tuvo éxito al presionar para conseguir la revisión de la Ley Fundamental de Educación. Sin haber sido modificada desde la ocupación, esta revisión le agregó frases que enfatizaban la importancia de la educación para el bien de la nación, el 'espíritu comunitario' y la 'herencia 
de la tradición', en un intento descarado y limitado, aunque altamente simbólico, por limpiar a la educación japonesa de la mayor parte de su influencia occidental más visible y volver a las tradiciones 'nativas' de Japón.

¿Qué hay, entonces, del saber occidental? ¿Qué pasa con Dewey en la actualidad? Saito e Imai ${ }^{91}$ concuerdan en que hay cuatro escuelas principales del saber occidental manifiestas en los círculos teóricos educacionales del Japón actual: la Escuela Francesa de los Annales (Aires), análisis del poder (Bourdieu y Foucault), posmodernismo (Haberlas, entre otros) y filosofía de Dewey. Los más destacados entre este grupo de estudiosos de Dewey son Saito y Imai, ${ }^{92}$ Mori ${ }^{93}$ y Sugiura. ${ }^{94}$ Aunque se trata algo sobre la filosofía y pedagogía de Dewey en casi todos los tratados de filosofía de la educación japoneses y la Sociedad John Dewey de Japón continúa reuniéndose, a pesar de una disminución en su membresía, las ideas de Dewey parecen haber estado ampliamente confinadas a la fuerza conductora de estos pocos estudiosos. En realidad, incluso para ellos mismos, su trabajo parece reflejar menos sus ideas (tema ya familiar a estas alturas) para convertirse más bien en un símbolo de su decepción por la dirección de la sociedad japonesa bajo el neo confucianismo/nativismo. El llamado a las armas de Saito e Imai ${ }^{95}$ a los estudiosos de Dewey es característico:

A la luz de la necesidad actual de reconceptualizar y reconstruir la democracia en Japón, el papel [del estudioso de Dewey] es particularmente significativo ... [la] única tarea debe ser darse cuenta de la democracia mediante un enriquecimiento de la relación entre los sectores público y privado, en vistas de la cultura antidemocrática [de Japón] y proclamar la libertad de sus jóvenes de las manos invisibles del interés nacional y económico.

No es más que la salva más reciente de las duraderas batallas japonesas centradas en la tradición, la historia y la cultura, que revela la continua evolución de las construcciones del saber sobre referentes culturales específicos.

\section{Conclusiones}

La recepción temprana y tardía de John Dewey en Japón aporta mucho a las comprensiones teóricas de la transferencia del saber en educación. En primer lugar, como se aprecia en las aún existentes e irresolutas tensiones entre los neo confucianistas, los nativistas y el saber occidental, las antiguas 'tradiciones' no se alteran con facilidad y menos se eliminan, mediante ideas y modelos del 'exterior'. De hecho, si se toma como ejemplo el caso de Japón, las tradiciones indígenas tienden a utilizar el conocimiento transferido de maneras que fortalecen las tensiones y batallas del momento, haciendo de esta manera los procesos de descontextualización y re contextualización mucho más fuertemente dependientes del contexto de lo que logra alumbrar la investigación existente, a la vez que sugiere que lo 'externo' a menudo puede ser una dimensión de lo 'interno', articulándose de nuevas maneras. En segundo lugar, la adopción y el uso del conocimiento transferido ocurre primeramente en espacios ya predispuestos para esto desde un principio (como la Universidad de Waseda y entre los educadores 
cristianos que habían vivido en los Estados Unidos). Esto genera la necesidad de ampliar el foco de la investigación de la recepción misma a la posición de los receptores con respecto de otros en los debates sobre educación con valores (las dimensiones de 'conflicto político' del contexto). Esto, en cambio, nos da pistas sobre cómo y por qué ocurre el 'filtrado' y la adaptación selectiva del conocimiento transferido, como en el caso de los intelectuales japoneses, como Tanaka y el énfasis primario en el individuo de la filosofía de Dewey. Es decir, lo más común es que los procesos de selección transformen el conocimiento en armas (críticas dirigidas) de práctica continua para su uso contra oponentes intra contextuales o para llamados más generales contra el status quo dominante. Finalmente, la recepción de Dewey en 1919, luego aquella en la época de posguerra y su reinterpretación a lo largo del siglo pasado, muestra claramente la forma en que las fluctuaciones en la dinámica política nacional, apoyadas en las tradiciones del saber indígena, más que cualquier otra combinación de variable explicativas, predetermina lo que se podrá calificar como conocimiento educacional.

En última instancia, ni la recepción de Dewey en Japón ni su insignificante impacto histórico posterior tienden a apoyar una hipótesis de convergencia de conocimiento educacional con ningún otro lugar que Dewey haya visitado en el mundo o con algún modelo mundial emergente. Si se puede afirmar algo, entonces, será que el presente análisis ha servido de apoyo a cualquier hallazgo que sugiera la internacionalidad del movimiento educacional progresista y, por ende, ofrece una nota cautelar contra cualquier afirmación de que estamos experimentando una era similar de convergencia global y armónica, sin importar cuan llamativa o bien intencionada pueda ser esa idea. En el caso de Japón, el avance más fascinante a observar podría no ser la 'armonización' de Japón con occidente, sino la manera en que el surgimiento de China pudo influenciar y fortalecer los aspectos de la tradición china en el pensamiento japonés y, desde ahí reconfigurar y reposicionar la alianza neo confuciana, nativista y occidental nuevamente, un adelanto de lo que ya se pudo observar en el fervor de los 'valores asiáticos' ${ }^{96}$ interrumpidos por la crisis financiera asiática de 1997.

Entonces, claramente la marcha de una cultura mundial compartida no se aplica al caso japonés, dado que cada vez que Japón se ha abierto al mundo, sus tradiciones se han reagrupado y reafirmado. Tampoco esta apertura y cierre significa un zigzagueo dialéctico hacia algún tipo de síntesis hegeliana superior de los valores occidentales y la cultura mundial a la vez. Más bien, en vez de un movimiento tendiente a obtener mayor libertad, progreso y justicia, hoy vemos en Japón quizá la reafirmación más violenta de las fuerzas tradicionales desde el fin de la Segunda Guerra Mundial, como se evidencia en la exitosa Revisión de la Ley Fundamental de Educación, de diciembre de 2006. Sin embargo, de manera crucial, este 'tradicionalismo' no es sólo una represión de la voluntad del pueblo: los padres están entre quienes más resisten una flexibilización curricular, que alinearía a la educación japonesa con modelos experienciales y progresistas. ${ }^{97}$ No sólo Dewey ha desaparecido, sino que las tradiciones nativistas-neo confucianas parecen estarse mimetizando con la 'globalización' y las formas occidentales, de manera muy similar a como lo hicieron alguna vez con el modelo alemán, en un proceso que se hace más fácil en la medida que las nociones construidas de las 'tendencias globales en políticas' se vuelven cada vez más conservadoras. 


\section{Notas}

1. El primero en destacar esta paradoja fue Victor Kobayashi (1964), cuyo exhaustivo estudio aún se reconoce como el mejor informe histórico de la recepción de Dewey en Japón. Este estudio tiene una gran deuda con aquel, incluso aunque funcione para desarrollar y extender las implicancias teóricas de aquellos hallazgos.

2. Ver, por ejemplo, L. Feuer, "John Dewey's Sojourn in Japan," Teachers College Record 71, no. 1 (1969): 123-45; N. Saito, "Education for Global Understanding: Learning From Dewey's Visit to Japan," Teachers College Record 105, no. 9 (2003): 1753-773.

3. V. Kobayshi, John Dewey in Japanese Educational Thought (Ann Arbor: University of Michigan School of Education, 1964).

4. G. Steiner-Khamsi, "Transferring Education, Displacing Reforms," en Discourse Formation in Comparative Education, ed. J. Schriewer (Frankfurt/M: Peter Lang, 2000), 158.

5. Feuer, "John Dewey's Sojourn in Japan”; Kobayshi, John Dewey in Japanese Educational Thought.

6. S. Eisenstadt, "Some Observations on the Transformation of Confucianism (and Buddhism) in Japan," en Confucian Traditions in East Asian Modernity: Moral Education and Economic Culture in Japan and the Four Mini-Dragons, ed. T. Wei-Ming (Cambridge: Harvard University Press, 1966), 175-85; W. Smith, Confucianism in Modern Japan: A Study of Conservatism in Japanese Intellectual History (Tokyo: Hokuseido, 1959).

7. M. Lincicome, "The Historical Context of Japanese Education to 1945, " en Windows on Japanese Education ed. E. Beauchamp (New York: Greenwood Press, 1991), 11.

8. S. Yamashita, "Confucianism and the Japanese State, 1904-1945" en Confucian Traditions in East Asian Modernity ed. Wei-Ming, 132-54.

9. Los términos nativism y nativist (utilizados en la versión original en inglés), son aquellos que tradicionalmente han dominado la literatura académica en inglés al abordar este aspecto de la historia intelectual y educacional japonesa (ver, por ejemplo, B. Marshall, Learning to be Modern: Japanese political discourse on education (Boulder, CO: Westview, 1994); Lincicome, "The Historical Context of Japanese Education to 1945." Este artículo adopta dichos términos de acuerdo con el uso mencionado, notando que pueden causar extrañeza o incomodidad en los lectores actuales, pero argumenta que es preferible ante palabras similares como 'indigenous' (indígena), que podría inducir a error sobre una doctrina 'nativista' construida por actualidades previas a la influencia china (para mayor información sobre esto, ver: P. Dale, The Myth of Japanese Uniqueness (London: Routledge, 1988), J. Kitagawa, “The Japanese Kokutai: History and Myth,” History of Religions 13, no. 3 (1974): 214-25.

10. Lincicome, "The Historical Context of Japanese Education to 1945," 12.

11. Ibid., 14.

12. Ver Marshall, Learning to Be Modern; Kitagawa, "The Japanese Kokutai."

13. Lincicome, "The Historical Context of Japanese Education to 1945," 7.

14. P. Nosco, Confucianism and Tokugawa Culture (Princeton: Princeton University Press, 1988).

15. Lincicome, "The Historical Context of Japanese Education to 1945," 12.

16. S. Eisenstadt, Japanese Civilization: A Comparative View (Chicago: University of Chicago Press, 1996), 304. 
17. J. Schriewer, "The Method of Comparison and the Need for Externalization: methodological criteria and sociological concepts," en Theories and Methods of Comparative Education ed. J. Schriewer en cooperación con B. Holmes (Frankfurt: Peter Lang, 1990).

18. H. Watnabe, “They are Almost the Same as the Ancient Three Dynasties': The West as Seen Through Confucian Eyes in Nineteenth-Century Japan," en Confucian Traditions in East Asian Modernity ed. Wei-Ming (Cambridge: Harvard University Press, 1996): 119-31.

19. I. Buruma, Inventing Japan, 1853-1964 (New York: Random House, 2003), 45.

20. Ibid., 22.

21. B. Platt, Burning and Building: Schooling and State Formation in Japan, 1750-1890 (Cambridge, MA: Harvard University Asia Center, 2004); B. Platt, "Japanese Childhood, Modern Childhood: the nation-state, the school, and 19th century globalization, "Journal of Social History 38, no. 4 (2005): 965-85; Y. Shinya, Jinjō Chugakkō no Seiritsu [The Formation of Secondary Schools in the Meiji Era] (Fukuoka: Kyushu Daigaku Shuppankai, 1997); Lincicome, "The Historical Context of Japanese Education to 1945."

22. E. Beauchamp, "The Development of Japanese Educational Policy," en Windows on Japanese Education ed. E. Beauchamp (New York: Greenwood Press, 1991): 27-50.

23. A. Burks, "The Yatoi Phenomenon: an early experiment in technical assistance," en Foreign Employees in Nineteenth-century Japan, eds. E. Beauchamp y A. Iriya (Boulder, CO: Westview Press, 1990).

24. B. Marshall, "Professors and Politics: The Meiji Academic Elite," Journal of Japanese Studies 3, no. 1 (1977): 71-97.

25. Lincicome, "The Historical Context of Japanese Education to 1945," 15.

26. Beauchamp, "The Development of Japanese Educational Policy."

27. A. Swale, The Political Thought of Mori Arinori: a study in Meiji conservatism (Surrey: Curazon Press, 2000).

28. G. Hoston, "The State, Modernity, and the Fate of Liberalism in Prewar Japan," The Journal of Asian Studies 51, no. 2 (1992): 287-316.

29. Buruma, Inventing Japan 1853-1964, 53.

30. Para un informe similar con mayores detalles sobre el período, ver J. Schriewer, "Multiple Internationalities: The Emergence of a World-Level Ideology and the Persistence of Idiosyncratic World-Views," en Transnational Intellectual Networks: Forms of Academic Knowledge and the Search for Cultural Identities (Frankfurt: Campus Verlag, 2004): 473-87.

31. J. Bartholomew, "Japanese Modernization and the Imperial Universities, 1876-1920," The Journal of Asian Studies 37, no. 2 (1978): 251-71.

\section{Kobayshi, John Dewey in Japanese Educational Thought.}

33. El uso del término 'liberal' para definir a cualquiera de los actores japoneses descritos en este estudio es mucho menos directo de lo que podría parecer en un principio. Esto se debe a que el término, en Japón como en cualquier otro lado, tiene varios significados, como libertad del individuo, sistema parlamentario de gobierno, desarrollo irrestricto (económico, social, político, cultural, etc.), garantía del gobierno a las libertades individuales y/o civiles, de manera que uno (como Mori) puede ser 'liberal' en algunos aspectos y en otros no. El lector de este estudio además tiene su(s) propia(s) definición(es) de liberalismo, como John Dewey y otros. El punto es que los ambiguos términos 'liberal' y 'progresista' logran hacer comprensible este documento, aunque para lograr eso arriesgan la posibilidad de confundir las verdaderas diferencias entre ciertas figuras, grupos y saberes individuales; estos cuestionamientos son inherentes a los procesos de recepción y adopción abordados aquí, 
pero por motivos de espacio no se les dará el tratamiento profundo que merece este tipo de complejidades.

34. Feuer, "John Dewey's Sojourn in Japan," 4.

35. Lincicome, "The Historical Context of Japanese Education to 1945."

36. Feuer, "John Dewey's Sojourn in Japan."

37. I. Nitobe, Bushidō: The Soul of Japan (Tokyo: Shokobo, 1901).

38. John Dewey, Reconstruction in Philosophy (New York: Henry Holt \& Co., 1920).

39. Quizá sea interesante contrastar la relativa autonomía de la que Dewey gozó en su viaje a Japón con la bombástica recepción y "meticulosa orquestación" de su viaje a China por su afiliación con $\mathrm{Hu}$ Shi (véase el artículo de Schulte sobre la recepción de Dewey en China en este número).

40. Feuer, "John Dewey's Sojourn in Japan."

41. Citado adentro Kobayashi, John Dewey in Japanese Educational Thought, 39.

42. Feuer, "John Dewey's Sojourn in Japan."

43. Kobayashi, John Dewey in Japanese Educational Thought.

44. Bartholomew, "Japanese Modernization and the Imperial Universities, 1876-1920," 253.

45. Ibid.

46. Kobayashi, John Dewey in Japanese Educational Thought, 21.

47. Citado adentro Kobayashi, John Dewey in Japanese Educational Thought, 20.

48. Feuer, "John Dewey's Sojourn in Japan," 2.

49. Kobayashi, John Dewey in Japanese Educational Thought, 85.

50. Citado adentro Kobayashi, John Dewey in Japanese Educational Thought, 41. El propio Dewey estaba muy conciente de la polarización, tanto de las tradiciones políticas como intelectuales, además de las razones que habían motivado que lo invitaran a dar conferencias en Japón: entregar una alternativa a las ideologías radicales de izquierda. Relata una conversación con el Barón Shibusawa, quién financió la mayor parte de los gastos del viaje de Dewey: "Explicó por alrededor de media hora su teoría [confuciana] de la vida ... y lo que intenta hacer, en especial que no se trata de un mero relevo. Se halla deseoso de conservar los antiguos estándares confucianos, sólo que adaptados a las condiciones económicas actuales; esencialmente, se trata de una moralidad de relaciones económicas feudales, como quizá ya lo sepa, y él opina que se puede lograr que los empleadores modernos de las fábricas adopten la antigua actitud paternal hacia los empleados y, así, evitar la lucha de clases. Los radicales de acá se ríen ante esa noción, tal como lo harían en los Estados Unidos, aunque por mi parte, si puede derrotar la teoría marxista de la evolución social e introducir algún otro tipo de evolución social, no veo porqué no debería venir por su dinero" J. Dewey and A. Dewey, Letters from China and Japan (New York: E.P. Dutton \& Company, 1920).

51. Y. Watanabe, Yasuhiro, Natorupu to Dyui [Natrop or Dewey?] (Tokyo: Bunkyō Shoin, 1924).

52. Tanaka es claramente el equivalente en el contexto japonés de Hu Shi en China (véase el artículo de Schulte en este número). Una comparación del papel crucial que estas dos figuras jugaron en la introducción y recepción de Dewey en estos dos contextos es merecedora de un análisis que tenga como objeto el papel de las redes personales en la diseminación y difusión del conocimiento educativo y de los "modelos" internacionales. 
53. S. Nolte, "Industrial Democracy for Japan: Tanaka Odō and John Dewey," Journal of the History of Ideas 45, no. 2 (1984): 280.

54. Citado adentro Kobayshi, John Dewey in Japanese Educational Thought.

55. Citado adentro Kobayshi, John Dewey in Japanese Educational Thought, 34.

56. Nolte, "Industrial Democracy for Japan," 278.

57. Eisenstadt, Japanese Civilization, 89; S. Nolte, "Individualism in Taishō Japan," The Journal of Asian Studies 43, no. 4 (1984).

58. Nolte, "Industrial Democracy for Japan."

59. Ibid., 290.

60. Kobayshi, John Dewey in Japanese Educational Thought, 155.

61. Ibid., 108.

62. K. Ohkura, "Dewey and the Ambivalent Modern Japan," en Inventing the Modern Self and John Dewey: Modernities and the Traveling of Pragmatism in Education, ed. T. Popkewitz (New York: Palgrave Macmillan, 2005), 290.

63. A. Gordon, Labor and Imperial Democracy in Prewar Japan (Berkeley: University of California Press, 1991).

64. Buruma, Inventing Japan, 1853-1964, 105.

65. Marshall, "Professors and Politics," 136.

66. Kobayshi, John Dewey in Japanese Educational Thought, 23.

67. K. Tsurumi, Kazuko, Amerika kokumisei no kenkyu - Dyui no Amerkia kokuminsei hihan no hitotsu sokumen [Research on American National Character: An Aspect of Dewey's Criticism of American National Character] (Tokyo: Taiheiyō Kyokai Shuppanbu, 1944).

68. D. Stegewerns, "Yoshino Sakuzo: The Isolated Figurehead of the Taisho Generation," en Nationalism and Internationalism in Imperial Japan: Autonomy, Asian Brotherhood, or World Citizenship? ed. D. Stegewerns (London and New York: Routledge Curzon, 2003).

69. J. Dower, Embracing Defeat: Japan in the wake of World War II (New York: W.W. Norton, 2000).

70. E. Beauchamp, “The Development of Japanese Educational Policy, 1945-1985," History of Education Quarterly 27, no. 3 (1987): 299-324.

71. N. Saito y Y. Imai, "In Search of the Public and Private: Philosophy of Education in Post-War Japan," Comparative Education 40, no. 4 (2004): 584.

72. G. Tsuchimochi, Education reform in postwar Japan: the 1946 U.S. Education Mission (Tokyo: University of Tokyo Press, 1993).

73. Kobayshi, John Dewey in Japanese Educational Thought.

74. M. Shibata, Japan and Germany under the US Occupation: A Comparative Analysis of Post-war Education Reform (Lanham, MD: Lexington Books, 2005).

75. Dower, Embracing Defeat.

76. Beauchamp, "The Development of Japanese Educational Policy, 1945-1985," 305.

77. Kobayshi, John Dewey in Japanese Educational Thought, 43.

78. Citado adentro Nolte, “Industrial Democracy for Japan," 279.

79. Kobayshi, John Dewey in Japanese Educational Thought, 109. 
80. Beauchamp, “The Development of Japanese Educational Policy, 1945-1985," 306.

81. Saito y Imai, "In Search of the Public and Private: Philosophy of Education in PostWar Japan," 586.

82. J. Meyer y F. Ramirez, "The World Institutionalization of Education," en Discourse Formation in Comparative Education, ed. J. Schriewer (Frankfurt/M: Peter Lang, 2000).

83. T. Kariya, Kaisoka Nihon to Kyöiku Kiki: fubyōdō saiseisan kara iyoku kakusa shakai he [Education in Crisis and Stratified Japan: from reproduction of inequality to incentive divide] (Tokyo: Yushindō, 2000).

84. Beauchamp, “The Development of Japanese Educational Policy, 1945-1985," 310.

85. K. Shimizu, Research on John Dewey [J. Dyuui Kenkyuu] (Tokyo: Bundou Shobo, 1970); S. Mori, The Relationship Between Japan's Education Reform Movement and Research on Dewey (Tokyo: The Bulletin of the Dewey Society, (1971); Y. Makino, Research on Dewey's Educational Perspectives (Tokyo: Fuuma Shobo, 1977).

86. Saito y Imai, "In Search of the Public and Private: Philosophy of Education in PostWar Japan," 587.

87. Ibid.

88. Ibid.; H. Kamidera, "Nihon ni okeru Dewey kenkyu" [Dewey studies in Japan], en Dewey kyoiku-ron no sho-mondai: Dewey tanjo hyaku-nen sai no kinnen shite [Fundamental Issues in the Philosophy and Educational Theory of John Dewey: contributions in commemoration of the hundredth anniversary of the birth of John Dewey] The John Dewey Society of Japan ed. (Tokyo: Tokyo Shoin, 1959); Kobyashi, John Dewey in Japanese Educational Thought.

89. Beauchamp, “The Development of Japanese Educational Policy, 1945-1985," 322.

90. Marshall, Learning to Be Modern, 254.

91. Saito y Imai, "In Search of the Public and Private: Philosophy of Education in PostWar Japan.”

92. Ibid.

93. A. Mori, Nihon ni okeru John Dewey shiso kenkyu-no seiri [A review of Dewey studies in Japan] (Tokyo: Shuo Sha, 1992).

94. H. Sugiura, ed. Nihon no sengo kyoiku to Dewey [Dewey and Postwar Japanese Education] (Tokyo: Sekai Shiso Sha, 1998).

95. Saito y Imai, "In Search of the Public and Private: Philosophy of Education in PostWar Japan," 592.

96. T. Wei-ming, Confucian Traditions in East Asian Modernity: Moral Education and Economic Culture in Japan and the Four Mini-Dragons (Cambridge: Harvard University Press, 1996); W. Cummings y P. Altbach, eds. The Challenge of Eastern Asian Education: Implications for America (Albany, NY: SUNY Press, 1997).

97. R. Goodman, "The Why, What and How of Education Reform in Japan," en Can the Japanese Change their Education System? eds. R. Goodman y D. Phillips (Oxford: Symposium Books, 2003). 
